Document downloaded from:

http://hdl.handle.net/10251/100593

This paper must be cited as:

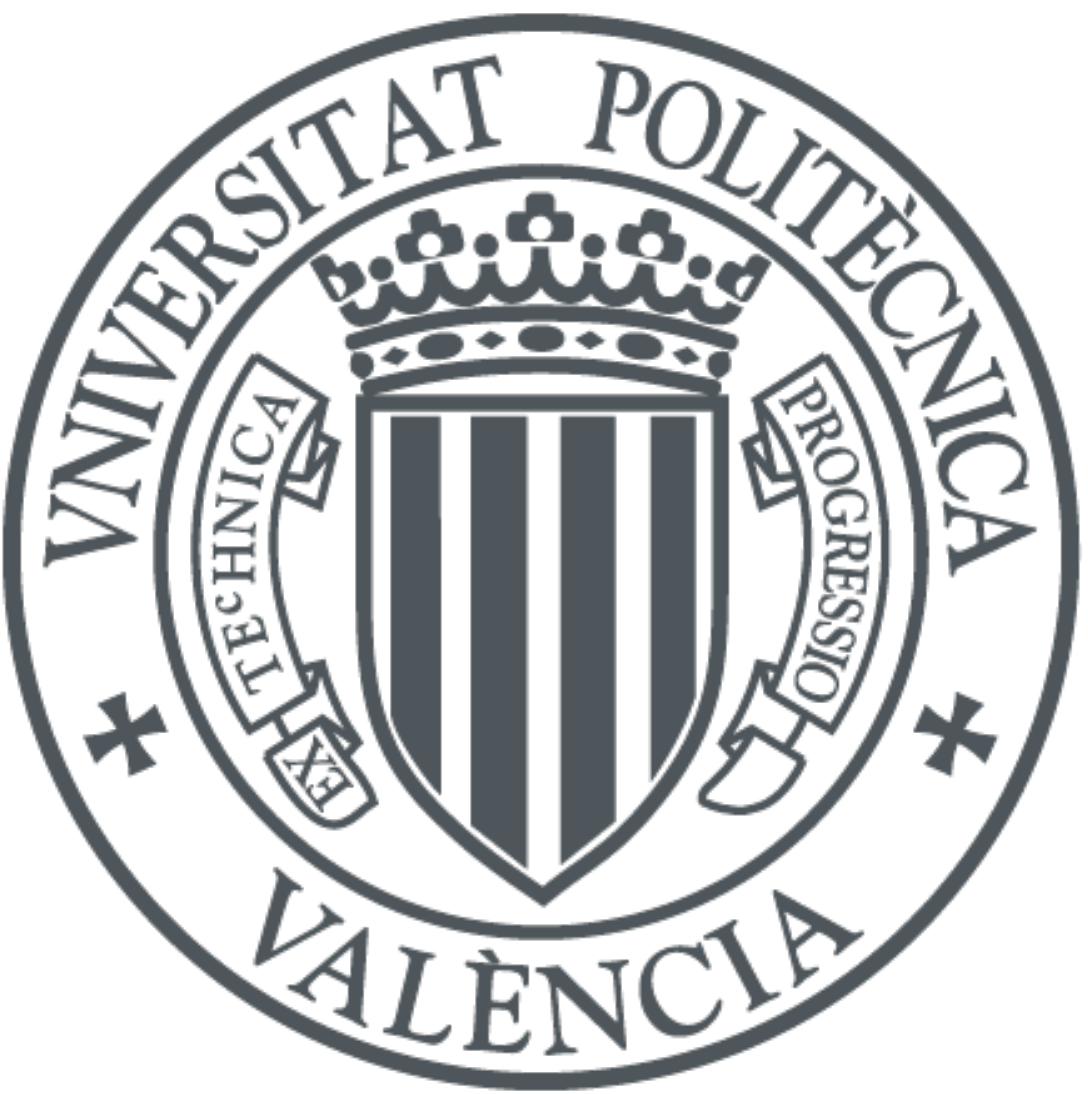

The final publication is available at

https://doi.org/10.1002/(SICI)1097-0126(199611)41:3<337::AID-PI625>3.0.CO;2-8

Copyright John Wiley \& Sons

Additional Information 


\title{
Dielectric Relaxation in Chlorinated Polyethylene-Polypropylene Copolymers*
}

\author{
Maria Jesús Sanchis, Enrique Sánchez Martínez, Ricardo Díaz Calleja\# \\ Departamento de Termodinámica Aplicada, E.T.S.I.I. Universidad Politécnica de Valencia, Aptdo. \\ 22012, 46071 Valencia, Spain.
}

\section{Eugenia T. Pankratova, Igor Murin}

Departament of Chemistry, St. Petersburg State University, Universitetskaya nab. 7/9, 199164 St. Petersburg, Russia

\begin{abstract}
Dielectric relaxation measurements were carried out in eight chlorinated polyethylene-polypropylene copolymers (PEPP) in the range of temperatures covering the main dielectric absorption. Chlorination of PEPP is expected to change the dynamic dielectric properties gradually with increasing amount of chlorine in the polymer chains. Thus, in the present study, increasing degrees of chlorination give a clear shift of the $\mathrm{T}_{\mathrm{g}}$-temperature towards higher values, excepting in the range between $40-51 \%$ chlorine where an anomalous behaviour was observed. The same tendency is also observed in the strength of the relaxation $(\Delta \varepsilon)$. The value $\Delta \varepsilon$ has been evaluated by using a non linear squares regression program (LEVM6) to calculate the parameters of Havriliak-Negami empirical equation. It does appear reasonable to assume that the anomalous observed behaviour can be attributed to a compensation of the dipolar moments of chlorine groups in the macromolecules.
\end{abstract}

Key words: chlorinated polyethylene-polypropylene copolymers, dynamic dielectric properties, Fuoss-Kirkwood and Havriliak-Negami empirical equations.

\footnotetext{
* The authors wish to dedicate this paper to Professor Günter Klar on the occasion of his sixtieth Birthday.
} 


\section{INTRODUCTION}

It is well know that the substitution of chlorine atoms in polyolefines and polyvinylchloride leads to a considerable change of physical properties ${ }^{1,2}$, and also, that the dielectric activity of non polar polymers is increased via decoration with polar groups. For example, the polyethylene (PE) is rendered dielectrically active by introducing carbonyl $(>\mathrm{C}=\mathrm{O})$ and chlorine $(-\mathrm{Cl})$ groups in the chain. ${ }^{3,4}$

In the present work, we have studied the effect of the addition of chlorine atoms on the dielectric properties for a set of eight chlorinated polyethylene-polypropylene copolymers (PEPP) and we tried to correlate several characteristic parameters $\left(\mathrm{T}_{\mathrm{g}}\right.$, relaxation intensity, position of dielectric loss peak,...) with the chlorine content.

This system allows us the study of the change of dynamic dielectric properties with increasing the amount of chlorine in the polymer chains. Although, it can be expected that chlorination of PEPP changes gradually the dielectric properties with the of chlorine content, it is possible that at certain content of chlorine atoms, dipole-dipole interactions became important and consequently the dielectric properties could reflect this fact.

For example, it is well known, that the $\alpha$ peak relaxation can be correlated with the glass transition temperature $\left(\mathrm{T}_{\mathrm{g}}\right)$, and this parameter varies widely with structure and other parameters (intermolecular forces, intrachain steric hindrance, symmetrical substitution, bulky stiff side groups,....). But the most important factor affecting the glass transition temperature is the chain flexibility, governed by the nature of the chemical groups which constitute the main chain. The incorporation of side groups on the main chain which impede rotation and stiff the chain clearly cause a large increase in $T_{g}$, and on the other hand, the presence of polar groups tends to raise $T_{g}$ more than non-polar groups of equivalent size, because the polar interactions will restrict rotation. According to this concept, with increasing degree of chlorination of PEPP copolymers, the glass temperature would rise, since the chains would be expected to become less flexible, and the cohesive forces between the chains become even stronger when the number of dipoles $\left(\mathrm{Cl}\right.$ atoms) on the polymer chains increase. Recently, Hößelbarth ${ }^{2}$ has studied, by DSC measurements, the variation of the glass temperature $T_{\mathrm{g}}$ with increasing chlorine content for chlorinated polyethylene (PE-C) and chlorinated polyvinylchlorid (PVC-C), 
and he has found a continuous rise of the $\mathrm{T}_{\mathrm{g}}$ with the degree of chlorination in both cases.

\section{EXPERIMENTAL}

\section{Preparation of polymers}

The eight chlorinated ethylene and propylene copolymers studied, were synthesized at $293 \mathrm{~K}$ in the presence oligoazine of diacetyl without light irradiation. The degree of chlorination ( $\%$ chlorine in mass), mass weight and the distribution of chlorine atoms on different groups are summarized in Table 1. The chlorination process, the molecular structure of these chlorinated samples and the distribution of chlorine atoms have been described in a previous paper ${ }^{5}$.

\section{Dielectric measurements}

Dielectric relaxation measurements by the conventional a.c. technique were carried out with a DEA 2970 equipment from TA Instruments at twenty frequencies over the range $10^{-1}$ and $10^{5} \mathrm{~Hz}$. The samples were moulded on disc-shaped pill of $1 \mathrm{~mm}$ thickness. The temperature ranges in each case where selected in order to capture the glass-rubber relaxation region. The frequency scans were taken at a heating rate of $1^{\circ} \mathrm{C} \cdot \mathrm{min}^{-1}$.

\section{RESULTS AND DISCUSSION}

The temperature dependence of the dielectric loss $\varepsilon$ " for eight PEPP copolymers with different degrees of chlorination at $100 \mathrm{~Hz}$ is shown in Figure 1. We can see in this plot that the position in the temperature axis of the loss peak shifts progressively to higher temperatures except in the range between $40-51 \%$ chlorine content where it is observed that the peak corresponding to the $\alpha$ relaxation passes through a maximum for $40 \%$ of chlorine, decrease until the chlorine content is $51 \%$ and then increase again.

As an example, the imaginary part of the dielectric permittivity as a function of the temperature at different frequencies and as a function of the frequency at different temperatures (in the range where $\alpha$ relaxation is presented) for one of the PEPP copolymers studied can be seen in Figure 2. 
In order to have a better understanding of the observed behaviour for the variation of the temperatura of the maximum of the loss peak $\left(\varepsilon^{\prime \prime}\right)$ with the degree of chlorination of PEPP, we represent in figure 3 the temperature of the loss peak $(100 \mathrm{~Hz})$ as a function of the chlorine content for the eight samples studied, as well as the corresponding values for PVC and PVDC taking from bibliography ${ }^{6}$.

To explain the above peculiar behaviour, we have compared the experimental data of $\alpha$ relaxation peak observed for each one of chlorinated PEPP copolymers with that one assigned to other related polymers ${ }^{2,6}$. Thus, in spite of the increase in chlorine groups, the $\mathrm{T}_{\mathrm{g}}$ for the polyvinylidine chlorine (PVDC), $254.9 \mathrm{~K}$, is about $98 \mathrm{~K}$ lower than the value of $353.6 \mathrm{~K}$ for the polyvinyl chlorine (PVC). According to Würstlin ${ }^{7}$ this difference arises from the dipole-dipole interactions in the case of PVDC owing to a partial compensation of the two $\mathrm{C}-\mathrm{Cl}$ dipoles. However, a comparison with the case of the non-polar polyisobutylene (PIB, 202K) or with other polar polymers as the polyvinylidene fluoride (PVDF, 238K), polyvinyl fluoride (PVF, 303K) and polyvinyl bromide (PVBr, 373K) suggest that the steric factors may be largely involved. So, the temperature of the glass transition is about $50 \mathrm{~K}$ lower for PVF than the PVC. This difference probably arises from lower steric hidrances to main-chain rotations, in the case of PVF since the radius of fluorine is less than that corresponding to chlorine. Differences in polarity seen unlikely to be involved to a large extent, as evidenced by the fact that the dipole moment of $\mathrm{CH}_{3} \mathrm{Cl}(1.87 \mathrm{D})$ is only slightly larger than that of $\mathrm{CH}_{3} \mathrm{~F}$ (1.81D). According to it the anomalous behaviour observed could be related to a steric repulsion between groups more voluminous in alternate chain atoms, which is thought to lead to a distortion of main-chain valences angles.

\section{Modelling of the relaxation peaks}

It is interesting to fit the empirical data to some empirical model in order to get information from the characteristics parameters of these empirical model. Therefore, in our case the peaks are fitted by an empirical equation of the type ${ }^{8}$

$$
\varepsilon^{\prime \prime}=\varepsilon^{\prime \prime}{ }_{\max } \cdot \operatorname{sech} \mathrm{m} x
$$


with $x=\frac{f_{\max }}{f}$, where $f_{\max }$ is the frequency at which the peak reaches a maximum and $\mathrm{m}$ $(0<\mathrm{m}<1)$ is a parameter dependent on temperature and frequency, which is related to the inter- and intramolecular interaction among the relaxing species in such a way that the larger is the parameter (the unity is its maximum value), the lower are the interactions. The results summarized in Table 2 suggest that the dipolar interactions are higher in PEPP copolymers with high chlorine contents, as a consequence of the higher concentration of dipoles per unit of the volume in the polymer.

In order to quantify more closely the dielectric relaxation processes we represent them in terms of Cole Cole plot, that is, a plot of $\varepsilon^{\text {" }}$ against $\varepsilon^{c}$. Whereas for Debye type peaks these plots are semicircles, the complex diagram plots representing the dielectric results associated with the dielectric relaxation are skewed arcs. The curves are customarily fitted by the Havriliak-Negami (HN) empirical equation ${ }^{9}$

$$
\varepsilon^{*}=\varepsilon_{\infty}+\frac{\varepsilon_{0}-\varepsilon_{\infty}}{\left[1+\left(i \omega \tau_{0}\right)^{\alpha}\right]^{\gamma}}
$$

where $\varepsilon_{0}$ and $\varepsilon_{\infty}$ are the relaxated and unrelaxated dielectric permittivity of the relaxation process, $\Delta \varepsilon$ is the relaxation strengh, $\tau_{0}$ is the central relaxation time, $\omega$ is the angular frequency and $\alpha, \gamma$ are parameters related with the shape and skewness of complex dielectric plot ( $\alpha$ is a parameter characterizing a symmetrical broadening of the distribution of relaxation times and $\gamma$ characterizes an asymmetrical broadening).

The values of $\mathrm{HN}$ parameters, at different temperatures for the chlorinated PEPP studied, were calculated by using the Complex Nonlinear Least Squares Immitance Fitting Program LEVM6 written by Ross McDonald ${ }^{10}$. The equivalent electric circuit ( a parallel configuration involving a condenser, and a Havriliak-Negami type impedance, $\left.\mathrm{Z}_{\mathrm{HN}}=\left[1+\left(\mathrm{i} \omega \tau_{0}\right)^{\alpha}\right]^{\gamma} / \mathrm{i} \omega\left[\mathrm{C}_{0}-\mathrm{C}_{\infty}\right]\right)$ employed in order to fit the experimental data to the model is depicted in Figure 4. The values for PEPP copolymer with a $64.3 \%$ of chlorine have been obtained using the strategy proposed in a previous paper ${ }^{11}$ to split the conductivity and interfacial phenomena. The best set of parameters obtained for different chlorinated PEPP samples at differents temperatures is given in Table 3 and the accuracy of the fit of $\mathrm{HN}$ parameters may be see in figure 5 and 6. 
In figure 7 are represented the values of the strenght relaxation $(\Delta \varepsilon)$ as a function of the chlorine content of the PEPP copolymers at $35^{\circ} \mathrm{C}$. The values of $\Delta \varepsilon$ at this temperature for copolymers with $55.6 \%$ dregree of chlorination were obtained assuming a linear variation of this parameter with the temperature ${ }^{12}$. The tendency of the value of the relaxed dielectric permittivity of the relaxation process $\left(\varepsilon_{0}\right)$ with the chlorine content (Table 3) are similar to that one observed for $\Delta \varepsilon$, that is, a progressive increase until $40 \%$ chlorine content, a decrease between $40-51 \%$ and again an increase and the variation of the parameter $\alpha$ is in inverse sense with that one observed for $\varepsilon_{0}$.

\section{Macroscopic correlation function}

According to the phenomenological theory of linear dielectric relaxation, the complex permittivity is related to the normalized decay function $\phi(t)$ by the expression ${ }^{13}$

$$
\frac{\varepsilon^{*}-\varepsilon_{\infty}}{\varepsilon_{0}-\varepsilon_{\infty}}=\int_{0}^{\infty} \frac{-\mathrm{d} \phi(t)}{\mathrm{d} t} e^{-i \omega t} \mathrm{~d} t
$$

where $\phi(t)$ is commonly expressed by the Kohlrausch-Williams-Watts (KWW) equation $^{14,15}$

$$
\phi(t)=\exp \left[-\left(\frac{t}{\tau_{\mathrm{KWW}}}\right)^{\beta}\right]
$$

with $\beta$ in the range $0<\beta<1$. The physical basis of the KWW equation was recently discussed by Ngai and co-workers. ${ }^{16,17}$ The model developed by these authors gives for $\phi(t)$ an expression similar to the KWW equation

$$
\phi(t)=\exp \left[-\left(\frac{t}{\tau^{*}}\right)^{(1-n)}\right]
$$

where $\tau^{*}$ represents the effective relaxated time and the parameter $n(0<n<1)$ is related to the coupling between the relaxating species, and its value is higher the larger is the coupling between relaxating species.

From the values of the components of $\varepsilon^{*}$ obtained by means of the $\mathrm{HN}$ equation and using methods described elsewhere ${ }^{18}$, the dipolar correlation function $\phi(t)$ was 
obtained. The values of the $\beta$ and $\tau_{\mathrm{Kww}}$ parameters for PEPP copolymers with higher chlorine content at different temperatures are given in Table 4 . It can be seen that the $\beta$ parameter at one specific temperature decreases when the chlorine content increases, suggesting that the interaction between chlorine units that take place in the dielectric glass-rubber process is higher when the number of these units in PEPP copolymer increases; and this parameter increase with temperature, for every PEPP copolymers.

\section{CONCLUSIONS}

Dielectric relaxation measurements for a set of eight chlorinated polyethylenepolypropylene copolymers reveal that the position of the $\alpha$-peak changes upon introduction of the chlorine units. In contrast with the results of Hößelbarth ${ }^{2}$ we observe at the increasing position of the $\alpha$-peak with the degree of chlorination until a degree of chlorination of $40 \%$, a decreasing until $51 \%$ and finally the position of the $\alpha$-peak increases with the chlorine content. The tendency of the increase of the position the of $\alpha$ peak can be related with the increase of rigidity of the chain by inserting chlorine groups. However, because of the high number of possible locations of the chlorine groups and their also high number possible relative position of them, a clear explanation of the tendency observed are not yet fully understood. 


\section{REFERENCES}

1 Petersen, J., Ranby, B., Makromol. Chem., 102 (1967) 83, 133 (1970) 263

2 Hößelbarth, B., Angew.Makromol. Chem., 231 (1995) 161

3 Ashcraft, C.R., Boyd, R.H., J.Polymer Science, 14 (1976) 2153

4 Matsuoka, S., Roe, R.J., Cole, H.F., A comparative study of dielectric behaviour of polyethylene and chlorinated polyethylene in "Dielectric Properties of Polymers" F. Karasz, Ed. Wiley 1972

5 Pankratova, E.T., Lubnin, A.B., Vysokomol.Soed. 28B (1986) N12 912

6 McCrum, N.G., Read, B.E., Williams, G., "Anelastic and Dielectric Effects in Polymeric Solids", Ed. Dover 1991

7 Würstlin, F. Kolloid Z., 120 (1951) 84

8 Fuoss, R.M., Kirkwood, J.G., J. Am. Chem. Soc. 63 (1941) 385

9 Havriliak, H., Negami, S., J. Polymer Scien. Part. C, 11 (1966) 99

10 Ross Macdonald, J., “Impedance Spectroscopy”, Ed. Willey, 1987

11 Sanchis, M. J., Díaz Calleja, R., Gargallo, L., Radic', D., Macromol. Rapid Commun. 15 (1994) 31

12 Buerger, D.E., Boyd, R.H., Macromolecules 22 (1989) 2694

13 Williams, G., Watts, D.C., Dev, S.B., North, A.M., Trans. Fadaray Soc., 67 (1971) 1323

14 Kohlrausch, R.,Prog. Ann. Phys., 12(3) (1947) 3931

15 Williams, G., Watts, D.C., Trans. Fadaray Soc., 66 (1970) 80

16 Ngai, K.L., Rajagopal, A.K., Teitler, S.J., J. Chem.Phys., 88 (1988) 5086

17 Ngai, K.L., Mashimo, S., Fytas, G., Macromolecules, 21 (1988) 3030

18 Nunes, R.C., Díaz-Calleja, R., Pinto, M., Saíz, E., Riande, E., J. Phys. Chem., 99 (1995) 12962 
Table 1. Chlorine content, molecular weight and distribution of Cl-atoms on differents groups for the eight chlorinated PEPP copolymers estudied.

\begin{tabular}{|l|c|c|c|c|c|c|}
\cline { 4 - 7 } \multicolumn{2}{c|}{} & \multicolumn{4}{c|}{$\begin{array}{c}\text { Distribution of Cl-atoms on } \\
\text { different groups }\end{array}$} \\
\cline { 2 - 7 } & Cl content in mass & $\mathbf{W}_{\mathbf{n}}\left(\mathbf{g}^{\prime} \cdot \mathbf{m o l}^{-1}\right)$ & $-\mathbf{C H}_{2} \mathbf{C l}$ & $=\mathbf{C H C l}$ & $\equiv \mathbf{C C l}$ & $-\mathbf{C H C l}_{\mathbf{2}}$ \\
\hline PEPP & $0 \%$ & 29000 & 0 & 0 & 0 & 0 \\
PEPP 2.5\% Cl & $2.5 \%$ & 28700 & 0.09 & 0.34 & 0 & 0 \\
PEPP 4.5\% Cl & $4.5 \%$ & 29300 & 0.17 & 0.62 & 0.1 & 0 \\
PEPP 6.5\% Cl & $6.5 \%$ & 28000 & 0.24 & 0.90 & 0.25 & 0 \\
PEPP 31\% Cl & $31 \%$ & 29400 & 1.16 & 6.20 & 1.40 & 0 \\
PEPP 40\% Cl & $40 \%$ & 28600 & 1.50 & 9.1 & 2.80 & 0.20 \\
PEPP 51\% Cl & $51 \%$ & 27800 & 2.70 & 12.3 & 2.80 & 0.20 \\
PEPP 55.6\% Cl & $55.6 \%$ & 29300 & 2.9 & 13.7 & 2.80 & 0.20 \\
PEPP 64.3\% Cl & $64.3 \%$ & 28500 & 3.3 & 13.7 & 2.80 & 1.30 \\
\hline
\end{tabular}


Table 2. Values of the parameter $m$ of the Fuoss-Kirkwood equation.

\begin{tabular}{|c|c|c|}
\hline & $\mathbf{T}\left({ }^{\circ} \mathrm{C}\right)$ & m \\
\hline \multirow[t]{3}{*}{$2.5 \% \mathrm{Cl}$} & -50 & 0.401 \\
\hline & -40 & 0.417 \\
\hline & -30 & 0.437 \\
\hline \multirow[t]{4}{*}{$4.5 \% \mathrm{Cl}$} & -45 & 0.202 \\
\hline & -40 & 0.208 \\
\hline & -35 & 0.218 \\
\hline & -30 & 0.225 \\
\hline \multirow[t]{5}{*}{$6.5 \% \mathrm{Cl}$} & -50 & 0.235 \\
\hline & -45 & 0.238 \\
\hline & -40 & 0.245 \\
\hline & -35 & 0.249 \\
\hline & -30 & 0.251 \\
\hline \multirow[t]{6}{*}{$31 \% \mathrm{Cl}$} & 15 & 0.228 \\
\hline & 20 & 0.259 \\
\hline & 25 & 0.287 \\
\hline & 30 & 0.320 \\
\hline & 35 & 0.339 \\
\hline & 40 & 0.372 \\
\hline \multirow[t]{5}{*}{$40 \% \mathrm{Cl}$} & 30 & 0.254 \\
\hline & 35 & 0.264 \\
\hline & 40 & 0.273 \\
\hline & 45 & 0.319 \\
\hline & 50 & 0.336 \\
\hline \multirow[t]{7}{*}{$51 \% \mathrm{Cl}$} & 20 & 0.184 \\
\hline & 25 & 0.197 \\
\hline & 30 & 0.206 \\
\hline & 35 & 0.219 \\
\hline & 40 & 0.222 \\
\hline & 45 & 0.253 \\
\hline & 50 & 0.268 \\
\hline \multirow[t]{4}{*}{$55.6 \% \mathrm{Cl}$} & 50 & 0.252 \\
\hline & 55 & 0.275 \\
\hline & 60 & 0.291 \\
\hline & 65 & 0.317 \\
\hline
\end{tabular}


Table 3. Havriliak-Negami Parameters $\left(\Delta \varepsilon, \varepsilon_{\infty}, \alpha, \gamma, \tau\right)$ for PEPP copolymers studied at different temperatures.

\begin{tabular}{|c|c|c|c|c|c|c|c|}
\hline & $\mathbf{T}\left({ }^{\circ} \mathbf{C}\right)$ & $\varepsilon_{\infty}$ & $\varepsilon_{0}$ & $\Delta \varepsilon$ & $\tau$ & $\alpha$ & $\gamma$ \\
\hline \multirow[t]{4}{*}{ PEPP $2.5 \%$ Cl } & -60 & 2.365 & 2.510 & 0.145 & & & \\
\hline & -50 & 2.362 & 2.487 & 0.125 & & & \\
\hline & -40 & 2.358 & 2.464 & 0.106 & & & \\
\hline & -30 & 2.355 & 2.44 & 0.085 & & & \\
\hline \multirow[t]{4}{*}{ PEPP $4.5 \% \mathrm{Cl}$} & -45 & 2.028 & 2.322 & 0.294 & $2.952010^{-2}$ & 0.302 & 0.745 \\
\hline & -40 & 2.000 & 2.325 & 0.325 & $4.356610^{-3}$ & 0.291 & 0.746 \\
\hline & -35 & 1.9532 & 2.3262 & 0.373 & $5.577110^{-4}$ & 0.284 & 0.757 \\
\hline & -30 & 1.943 & 2.319 & 0.376 & $1.714510^{-4}$ & 0.288 & 0.762 \\
\hline \multirow[t]{3}{*}{ PEPP $6.5 \% \mathrm{CI}$} & -40 & 2.191 & 2.740 & 0.627 & $1.983810^{-3}$ & 0.326 & 0.546 \\
\hline & -35 & 2.190 & 2.821 & 0.631 & $4.0034 \cdot 10^{-4}$ & 0.326 & 0.625 \\
\hline & -30 & 2.216 & 2.814 & 0.598 & $1.020610^{-4}$ & 0.337 & 0.708 \\
\hline \multirow[t]{4}{*}{ PEPP $31 \%$ CI } & 20 & 2.622 & 5.547 & 2.925 & $6.213410^{-3}$ & 0.402 & 0.600 \\
\hline & 25 & 2.618 & 5.425 & 2.807 & $1.120610^{-3}$ & 0.419 & 0.630 \\
\hline & 30 & 2.603 & 5.295 & 2.692 & $4.287210^{-3}$ & 0.480 & 0.540 \\
\hline & 35 & 2.592 & 5.269 & 2.677 & $1.332310^{-3}$ & 0.490 & 0.560 \\
\hline \multirow[t]{4}{*}{ PEPP $40 \%$ Cl } & 35 & 2.711 & 5.724 & 3.014 & $3.763110^{-2}$ & 0.380 & 0.800 \\
\hline & 40 & 2.717 & 5.617 & 2.900 & $6.517510^{-2}$ & 0.410 & 0.795 \\
\hline & 45 & 2.728 & 5.588 & 2.860 & $2.012310^{-3}$ & 0.440 & 0.730 \\
\hline & 50 & 2.722 & 5.520 & 2.798 & $8.687010^{-4}$ & 0.510 & 0.590 \\
\hline \multirow[t]{4}{*}{ PEPP 51\% Cl } & 25 & 2.475 & 5.401 & 2.926 & $4.953010^{-1}$ & 0.393 & 0.436 \\
\hline & 30 & 2.453 & 5.372 & 2.919 & $6.463910^{-2}$ & 0.406 & 0.449 \\
\hline & 35 & 2.432 & 5.340 & 2.908 & $1.190610^{-2}$ & 0.416 & 0.473 \\
\hline & 40 & 2.414 & 5.311 & 2.896 & $2.481610^{-3}$ & 0.421 & 0.499 \\
\hline \multirow[t]{4}{*}{ PEPP $55.6 \%$ Cl } & 50 & 2.616 & 5.204 & 2.588 & $8.804610^{-3}$ & 0.380 & 0.765 \\
\hline & 55 & 2.647 & 5.151 & 2.504 & $2.489010^{-3}$ & 0.426 & 0.726 \\
\hline & 60 & 2.651 & 5.081 & 2.430 & $2.620110^{-4}$ & 0.440 & 0.700 \\
\hline & 65 & 2.653 & 5.022 & 2.369 & $2.566010^{-4}$ & 0.490 & 0.626 \\
\hline PEPP $64.3 \% \mathrm{Cl}$ & 100 & 2.295 & 4.097 & 1.798 & $8.8441210^{-2}$ & 0.614 & 0.219 \\
\hline
\end{tabular}


Table 4. Values of the parameters that define the Kohlrauch-Williams-Watts (KWW) equation.

\begin{tabular}{|c|c|c|c|}
\cline { 2 - 4 } \multicolumn{1}{c|}{} & $\mathbf{T}\left({ }^{\circ} \mathbf{C}\right)$ & $\beta$ & $\tau_{\text {KWW }}$ \\
\hline $\mathbf{3 1 \%} \mathbf{C l}$ & 20 & 0.236 & $3.082 \cdot 10^{-3}$ \\
& 25 & 0.254 & $6.439 \cdot 10^{-4}$ \\
& 30 & 0.259 & $1.437 \cdot 10^{-3}$ \\
& 35 & 0.278 & $5.166 \cdot 10^{-4}$ \\
\hline $\mathbf{4 0 \%} \mathbf{C l}$ & 35 & 0.254 & $5.074 \cdot 10^{-2}$ \\
& 40 & 0.273 & $8.059 \cdot 10^{-2}$ \\
& 45 & 0.280 & $1.812 \cdot 10^{-3}$ \\
& 50 & 0.300 & $4.025 \cdot 10^{-4}$ \\
\hline $\mathbf{5 1 \%} \mathbf{C l}$ & 25 & 0.186 & $6.204 \cdot 10^{-2}$ \\
& 30 & 0.197 & $9.637 \cdot 10^{-3}$ \\
& 35 & 0.219 & $3.980 \cdot 10^{-3}$ \\
& 40 & 0.222 & $5.930 \cdot 10^{-4}$ \\
\hline $\mathbf{5 5 . 6 \%} \mathbf{C l}$ & 50 & 0.246 & $1.027 \cdot 10^{-2}$ \\
& 55 & 0.270 & $2.240 \cdot 10^{-3}$ \\
& 60 & 0.271 & $2.061 \cdot 10^{-4}$ \\
& 65 & 0.294 & $1.386 \cdot 10^{-4}$ \\
\hline
\end{tabular}




\section{Figure captions}

Figure 1. Temperature dependence of the dielectric loss $\varepsilon$ " for eight chlorinated PEPP copolymers studied at $100 \mathrm{~Hz} \quad(.2 .5 \%, 04.5 \%, \Delta 6.5 \%)$

Figure 2. Variation of the dielectric loss $\varepsilon$ " with (a) the temperature at different frequencies $\left(\bullet 10^{5} \mathrm{~Hz}, 010^{4} \mathrm{~Hz}, \square 10^{3} \mathrm{~Hz}, \square 10^{2} \mathrm{~Hz}, \diamond 10^{1} \mathrm{~Hz}, \diamond 10^{0} \mathrm{~Hz}, \Delta 10^{-1} \mathrm{~Hz}\right)$ and (b) the frequency at different temperatures $\left(\star 20^{\circ} \mathrm{C}, \bullet 25^{\circ} \mathrm{C}, \star 30^{\circ} \mathrm{C}, \square 35^{\circ} \mathrm{C}\right.$, $40^{\circ} \mathrm{C}, \diamond 45^{\circ} \mathrm{C}, \Delta 50^{\circ} \mathrm{C}, \diamond 55^{\circ} \mathrm{C}$ ) for PEPP copolymer with a chlorine content of $51 \%$.

Figure 3. Variation of the temperature of the maximum of the loss peak ( $\left.\varepsilon^{\prime \prime}\right)$ with the chlorine content for PEPP copolymers with $31,40,51,55.6 \% \mathrm{Cl}$ and other related polymers, $\triangle \mathrm{PVC}, \square \mathrm{PVDC}$.

Figure 4. Electrical circuit representing the dielectric process.

Figure 5. Complex plane representation of PEPP copolymers with a chlorine content of 31,40 and $51 \%$ at $35^{\circ} \mathrm{C}$ and $55.6 \%$ at $55^{\circ} \mathrm{C}$.

Figure 6. A plot of the residuals $\left(\varepsilon^{\prime}, \varepsilon^{\prime}\right)$ against log frequency is given here for PEPP copolymer with a chlorine content of $31(\bullet, 0), 40(\square, \square)$ and $51 \%(\diamond, \diamond)$ at $35^{\circ} \mathrm{C}$ and $55.6 \%(\Delta, \Delta)$ at $55^{\circ} \mathrm{C}$.

Figure 7. Variation of the streght of the relaxation with the chlorine content for PEPP copolymers at $35^{\circ} \mathrm{C}$ with at dregree of chlorination of $31,40,51,55.6 \%$. 


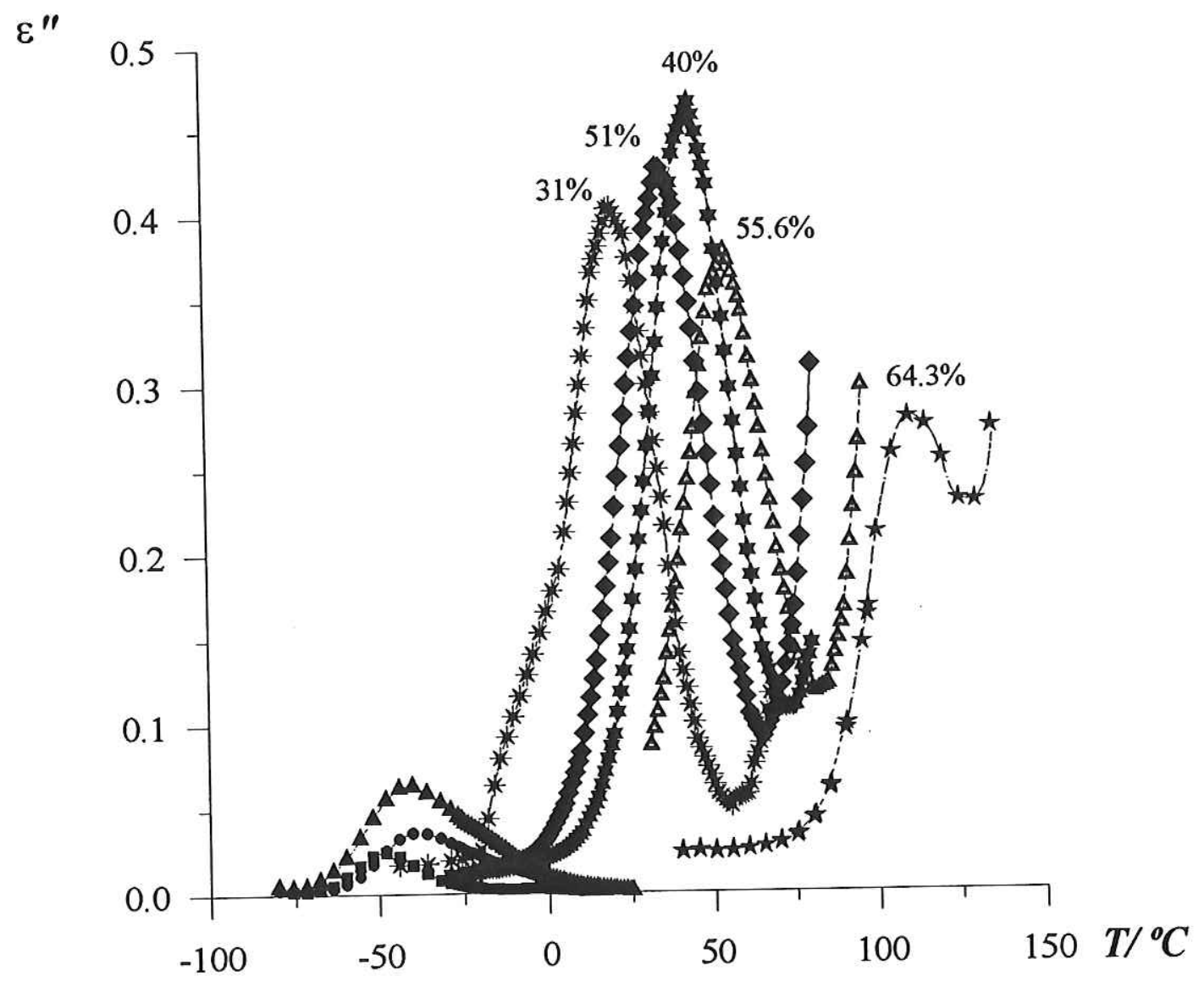

Figure 1

Maria Jesús Sanchis, Enrique Sánchez,

Ricardo Díaz-Calleja, Eugenia T.

Pankratova, Igor Murin

"Dielectric Relaxation in Chlorinated-...

Polypropylene Copolymers" 

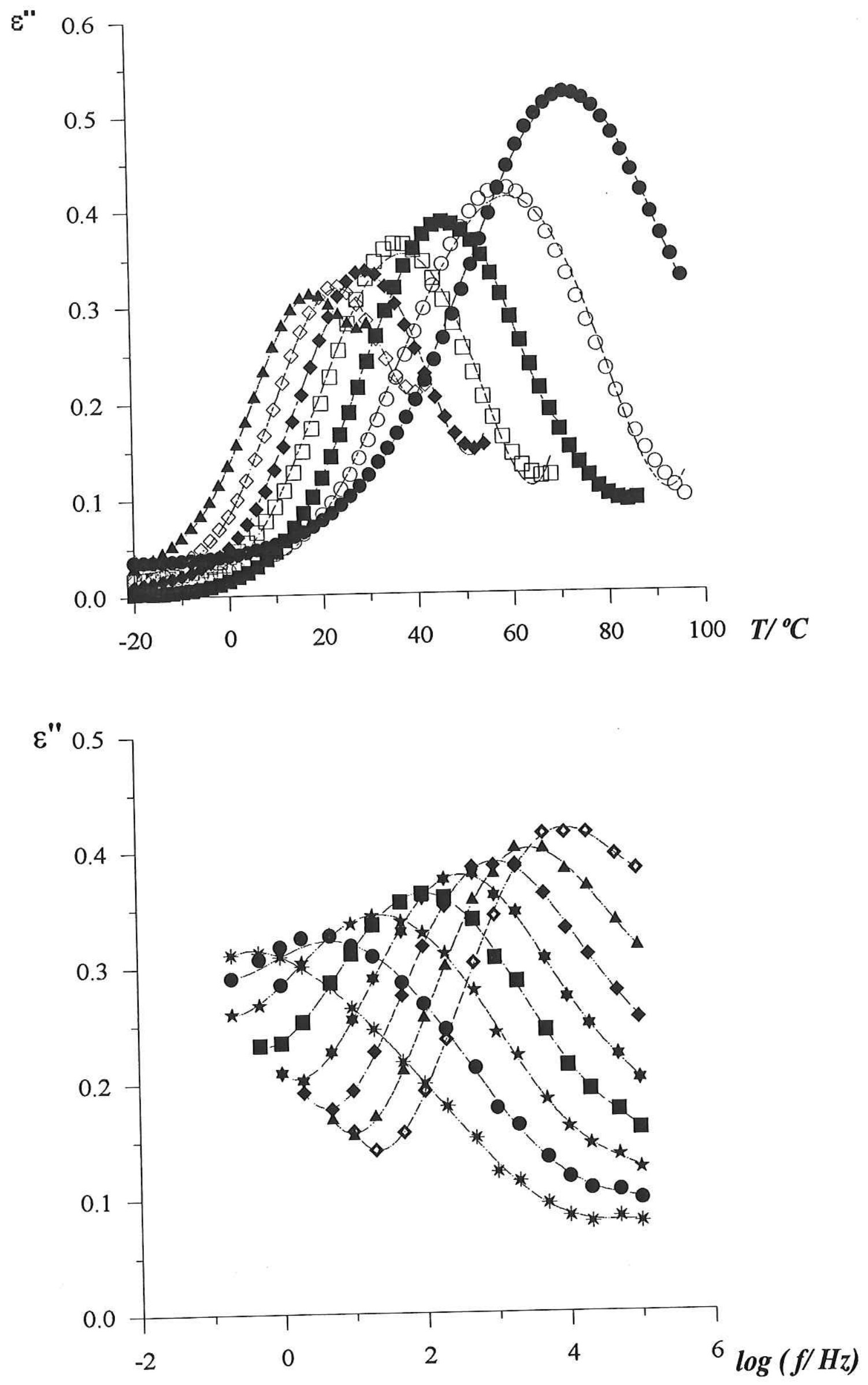


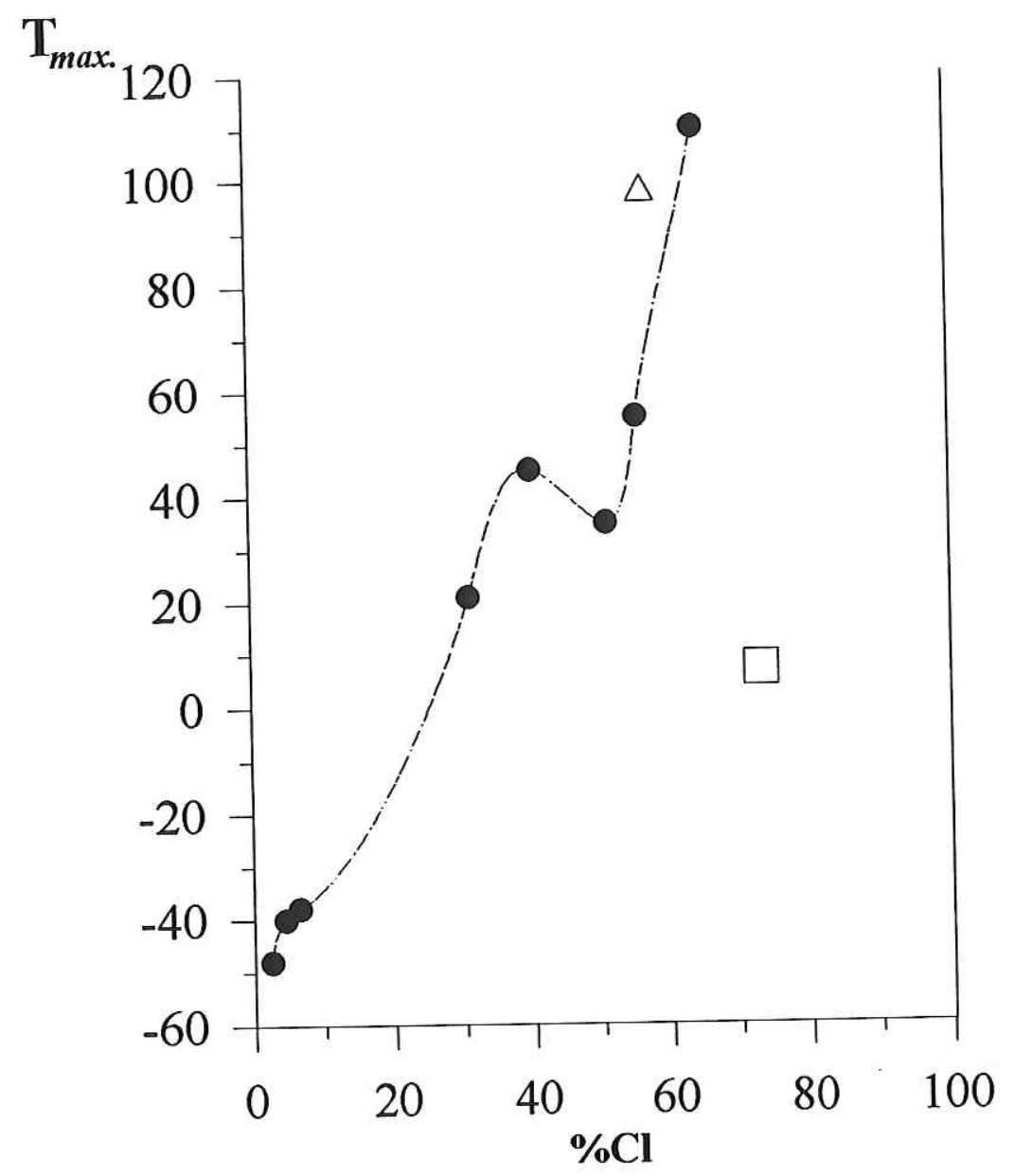

Figure 3

Maria Jesús Sanchis, Enrique Sánchez,

Ricardo Díaz-Calleja, Eugenia T.

Pankratova, Igor Murin

"Dielectric Relaxation in Chlorinated....

Polypropylene Copolymers" 


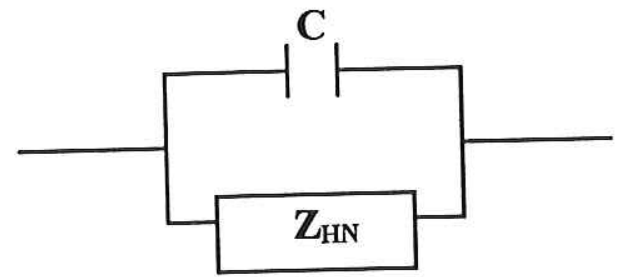

Figure 4

Maria Jesús Sanchis, Enrique Sánchez,

Ricardo Diaz-Calleja, Eugenia T.

Pankratova, Igor Murin

"Dielectric Relaxation in Chlorinated...

Polypropylene Copolymers" 

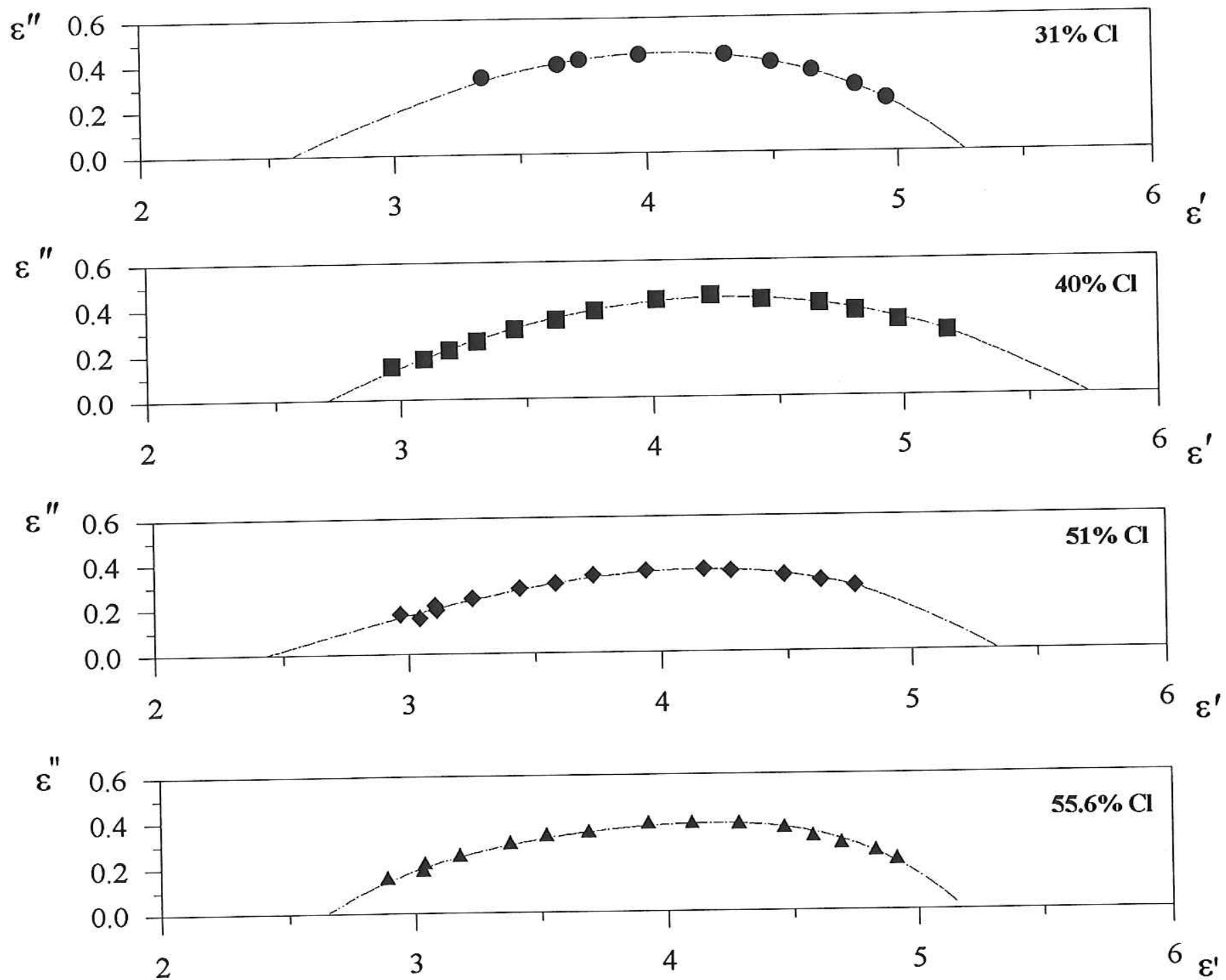

Figure 5

Maria Jesús Sanchis, Enrique Sánchez,

Ricardo Diaz-Calleja, Eugenia T.

Pankratova, Igor Murin

"Dielectric Relaxation in Chlorinated-.

Polypropylene Copolymers" 
Residuals from Real and Imaginary Dielecric Dispersion

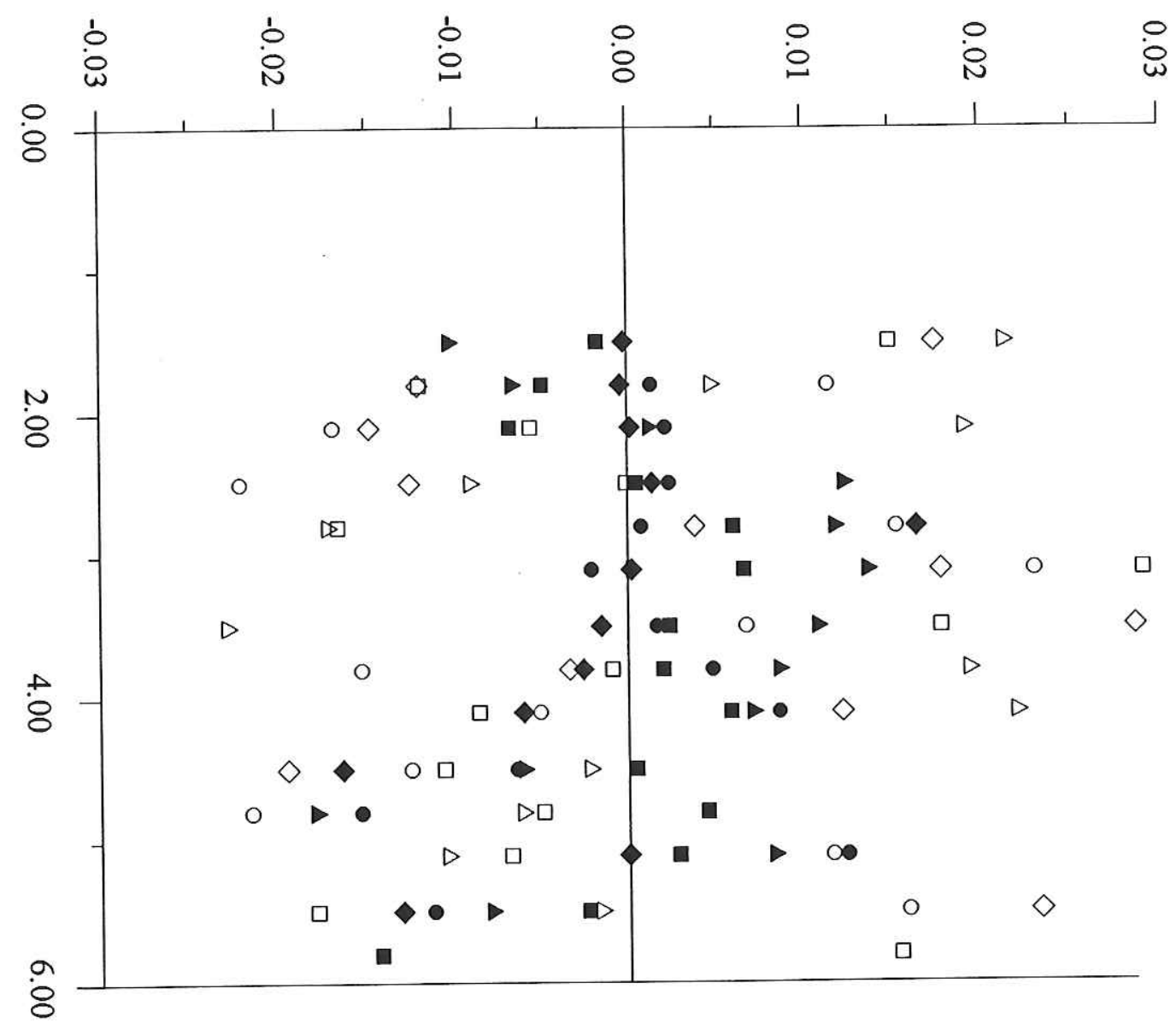

里

Figure 6

Maria Jesús Sanchis, Enrique Sánchez, Ricardo Diaz-Calleja, Eugenia T. Pankratova, Igor Murin

"Dielectric Relaxation in Chlorinated.. Polypropylene Copolymers" 


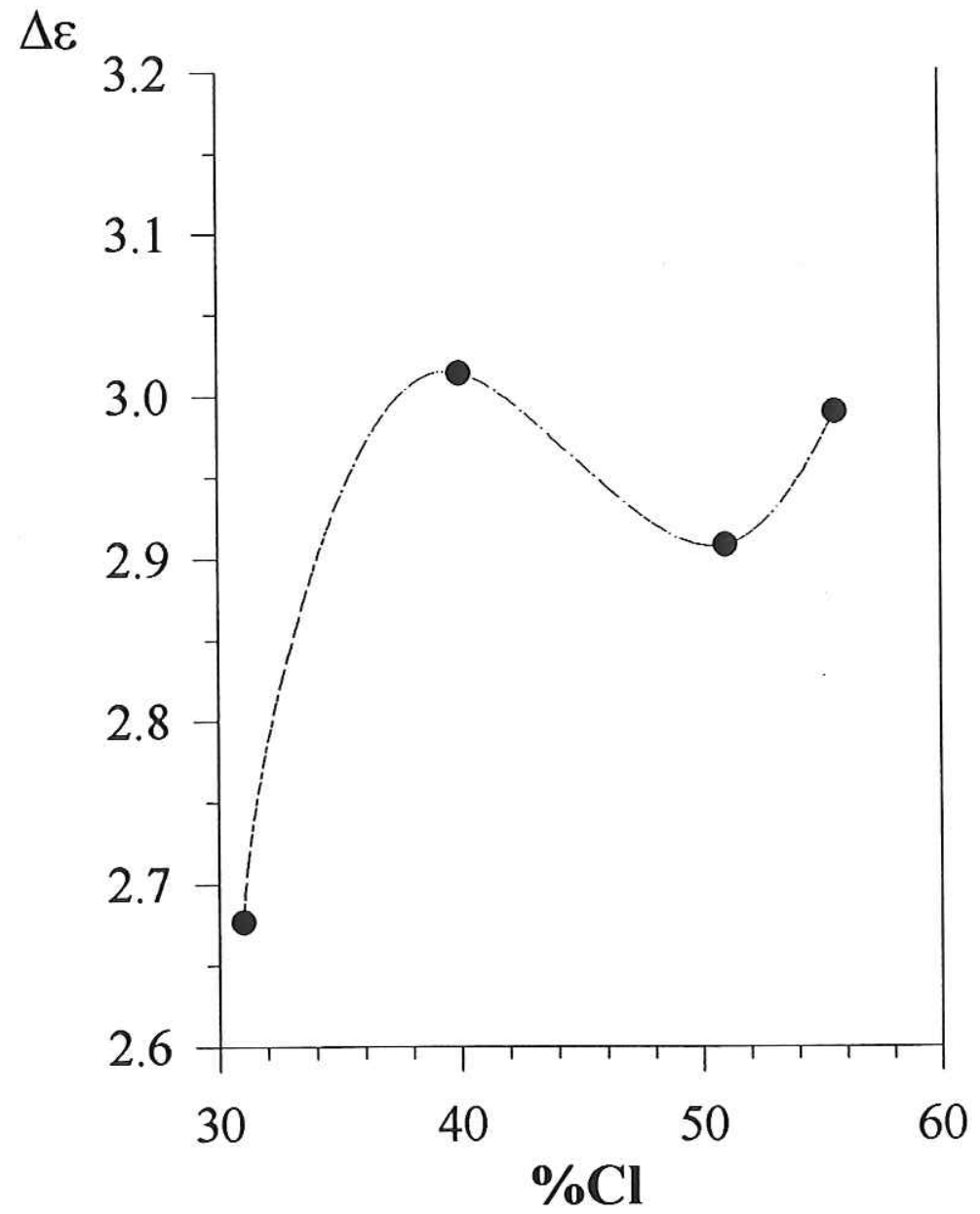

Figure 7

Maria Jesús Sanchis, Enrique Sánchez, Ricardo Día-Calleja, Eugenia T. Pankratova, Igor Murin "Dielectric Relaxation in Chlorinated.. Polypropylene Copolymers" 